\title{
Nasal Spray, Lyophilisate for Suspension Dosage Form
}

National Cancer Institute

\section{Source}

National Cancer Institute. Nasal Spray, Lyophilisate for Suspension Dosage Form. NCI Thesaurus. Code C149684.

Solid preparation consisting of a freeze-dried powder intended to be dispersed in the specified liquid to obtain a nasal spray, suspension. 